\title{
EDITORIAL
}

\section{Progress Report From Family Medicine for America's Health}

Glen Stream, MD

(Fam Med. 2019;51(2):84-86.)

doi: 10.22454/FamMed.2019.788765

amily Medicine for America's Health

- (FMAHealth) was developed as a follow up to the Future of Family Medicine Project (FFM) which published its report in $2004 .{ }^{1}$ Beginning in 2012 the family medicine organizations involved in FFM, joined by the American College of Osteopathic Family Physicians, undertook a research effort to understand the discipline's progress subsequent to the FFM report, identify its successes, and develop a strategic plan to address those areas where additional work was needed. The FMAHealth project and its supporting communication campaign, Health is Primary (www.healthisprimary.org), launched in October $2014 .^{2}$

At the start of FMAHealth, several writing groups evaluated the current health care landscape in which the project would take place as well as some of the opportunities and challenges involved. Papers from these groups explored partnering with patients, families, and communities to envision a new health care system for America, built on a foundation of transformed primary care and supported by comprehensive changes in primary care financing. To support this effort, papers addressed the necessary changes in workforce training, technology, and primary care research. These papers were published in a special issue of Family Medicine in September 2015. ${ }^{3-8}$

FMAHealth's strategic objectives are ambitious $^{2}$ :

1. Collaborate with patients, employers, payers, policy makers, and other primary care professionals to show the value and benefits of primary care, as well as the contribution that family physicians make in meeting the health and health care needs of people throughout the United States.

2. Work to ensure that every person in the United States understands the value of and has the opportunity to have a personal relationship with a trusted family physician or other primary care professional in the context of a medical home.

3. Family medicine will, in collaboration with our primary care partners, be accountable for increasing the value of primary care for the patients family physicians serve.

4. Collaborate with national stakeholders to reduce health disparities in the United States.

5. Lead the continued evolution of the patient-centered medical home to ensure that it is the best way to deliver comprehensive, patient-centered primary care to patients, families, and the communities family physicians serve.

6. Work to ensure that the country has the well-trained primary care workforce it needs for the future through expansion and transformation of training from pipeline through practice.

7. To give patients the comprehensive and coordinated care and attention they deserve, family medicine commits to moving primary care reimbursement away from fee-for-service and toward comprehensive primary care payment.

The strategic work of FMAHealth was organized with seven tactic teams reporting to the board. These teams include Technology, 
Practice, Payment, Workforce/Education, Research, Engagement, and Health Equity. Tactic teams conducted efforts of various types including formal research, convening expert panels, outreach regarding best practices and success stories, and collaboration with organizations outside of family medicine. This process is well summarized in a recent president's column in this journal. ${ }^{9}$ FMAHealth is now approaching the end of its planned 5-year duration. Four of the tactic teams sunset at the end of 2017 and the final three at the end of 2018. Now is an appropriate time to provide an update regarding some of their work. The papers in this issue are important samples of that work.

Research is the foundation of any discipline. The current state of research capacity in departments of family medicine ${ }^{10}$ and their scholarly output ${ }^{11}$ are presented here. Analysis of bright spots of successful research departments builds on this information to identify how to improve and expand the research foundation of the specialty. ${ }^{12}$

Enhancing patient-centeredness was a major focus of FMAHealth. The FMAHealth board includes a patient advocate member and has encouraged all its sponsor organizations to include patient advocates on their boards. FMAHealth encourages all practices to have a patient and family advisory committee or similar input mechanism to include the voice of the patient in the important decisions regarding care delivery. The FMAHealth Engagement Team collaborated with the Patient-Centered Primary Care Collaborative (PCPCC) to convene a multistakeholder process to develop the Shared Principles of Primary Care. ${ }^{13}$ These will serve as a foundation for advocacy efforts of the PCPCC and its member organizations promoting primary care including enhanced investment.

Ensuring a sufficient and well-trained family physician workforce is an important strategic focus of FMAHealth. A significant effort was made to better understand factors influencing specialty choice of medical students and how to increase the number choosing family medicine. ${ }^{14,15}$ The FMAHealth Workforce and Education Team, in collaboration with the sponsor organizations, set a goal of $25 \times 2030$ : that by the year $2030,25 \%$ of US medical students will choose to match in family medicine residencies. This ambitious goal is now being coordinated by the American Academy of Family Physicians (AAFP) in collaboration with other family medicine organizations.
Continuing to advance the medical home model supported by an improved primary care payment system is essential to the primary care foundation of US health care. The FMAHealth Practice Team devoted efforts toward better understanding and facilitating that transformation and identified bright spot examples to guide others. ${ }^{16,17}$ Central to this effort is changing the payment system for primary care. The FMAHealth Payment Team focused on developing an improved Comprehensive Primary Care Payment (CPCP) model and a calculator tool to facilitate the transition from traditional fee-for-service payment to $\mathrm{CPCP}^{18}$

Family medicine is uniquely positioned to advance health equity. Reducing health disparities is a primary focus of FMAHealth, and is woven through the work of all the tactic teams. The FMAHealth Health Equity Tactic Team devoted its work to identifying the current state of health disparities and to developing tools and resources to promote health equity. ${ }^{19}$

Much has been accomplished during the project to date, and much remains to be done. FMAHealth was organized as a time-limited collaboration of its eight sponsor organizations. Separate from FMAHealth, much important work has also been done during this time by our sponsoring organizations. Several important efforts begun by FMAHealth will be carried forward by one or more of the sponsor organizations, including:

- $25 \times 2030$ (coordinated by the AAFP),

- Evaluation of the EPAs (coordinated by AFMRD),

- Strategies to develop and support community preceptors (coordinated by STFM),

- Alliance for e-Health Advisory Group (coordinated by the AAFP),

- Research efforts (coordinated by NAPCRG), and

- Health equity initiatives (coordinated by the AAFP Center for Diversity and Health Equity).

During the course of this strategic work, a targeted communication effort, the Health is Primary campaign, has worked to raise awareness of issues facing primary care and the importance of primary care to achieving the triple aim. Originally-planned regional events were redirected to an "inside the beltway" focus in midcampaign to raise awareness among key stakeholders as well as the public. The FMAHealth board and the sponsor organizations consider the campaign to have been a success. 
The FMAHealth board will continue its work through the end of May 2019. During this time the board will review the results of the project from several perspectives:

- Successful work efforts accomplished,

- Lessons learned and what might have been done differently,

- Impact of FMAHealth on the health care environment in general and for family medicine in particular, and

- Work that remains to be done and how it might be accomplished, including how the sponsor organizations can continue to collaborate in the future.

A capstone article is planned to follow the conclusion of the project to document this information. Look for that in a future issue of this journal.

ACKNOWLEDGMENTS: On behalf of the FMAHealth Board, the author thanks all those who gave generously of their time and expertise working in the FMAHealth Tactic Teams.

CORRESPONDING AUTHOR: Address correspondence to Dr Glen Stream, Family Medicine for America's Health, LLC, 11400 Tomahawk Creek Parkway, Leawood, KS 66211. 442-666-8067. Fax: 913-906-6089. glenstreammd@fmahealth.org.

\section{References}

1. Martin JC, Avant RF, Bowman MA, et al. The Future of Family Medicine: a collaborative project of the family medicine community. Ann Fam Med. 2004;Mar-Apr;2(suppl 1):S3-32.

2. Phillips RL Jr, Pugno PA, Saultz JW, et al. Health is primary: family medicine for America's health. Ann Fam Med. 2014;12(2)(suppl 1):S1-S12.

3. Puffer JC, Borkan J, DeVoe JE, et al. Envisioning a new health care system for America. Fam Med. 2015;47(8):598 603.

4. Howrey BT, Thompson BL, Borkan J, et al. Partnering with patients, families, and communities. Fam Med. 2015;47(8):604-611.

5. Saultz JW, Jones SM, McDaniel SH, et al. A new foundation for the delivery and financing of American health care. Fam Med. 2015;47(8):612-619
6. Hughes LS, Tuggy M, Pugno PA, et al. Transforming training to build the family physician workforce our country needs. Fam Med. 2015;47(8):620-627.

7. Phillips RL Jr, Bazemore AW, DeVoe JE, et al. A family medicine health technology strategy for achieving the triple aim for US health care. Fam Med. 2015;47(8):628-635.

8. deGruy FV III, Ewigman B, DeVoe JE, et al. A plan for useful and timely family medicine and primary care research. Fam Med. 2015;47(8):636-642

9. Wilson SA. Family Medicine for America's Health-4 years later, heading into the future. Fam Med. 2018;50(5):399-402.

10. Weidner A, Peterson LE, Mainous III AG, et al. The current state of research capacity in US family medicine departments. Fam Med. 2019;51(2):112-119.

11. Liaw W, Petterson S, Jiang V, et al. The scholarly output of faculty in family medicine departments. Fam Med. 2019;51(2):103-111.

12. Liaw W, Eden A, Coffman M, et al. Factors associated with successful research departments: a qualitative analysis of family medicine research bright spots. Fam Med. 2019;51(2):87-102

13. Epperly T, Bechtel C, Sweeney R, et al. The shared principles of primary care: a multistakeholder initiative to find a common voice. Fam Med. 2019;51(2):179-184.

14. Alavi S, Ho T, Stisher C, et al. Factors that influence student choice in family medicine: a national focus group. Fam Med. 2019;51(2):143-148.

15. Kost A, Bentley A, Phillips J, et al. Graduating medical student perspectives on factors influencing specialty choice: an AAFP national survey. Fam Med. 2019;51(2):129-136.

16. Marker J, Davis KN, Etz R, et al. Report from the FMAHealth Practice Core Team: achieving the quadruple aim through practice transformation. Fam Med. 2019;51(2):193197.

17. Robinson C, Lee JW, Davis KN, et al. Findings from FMAHealth's Bright Spots in Practice Transformation Project. Fam Med. 2019;51(2):137-142.

18. George A, Sachdev N, Hoff J, et al. Development, value, and implications of a comprehensive primary care payment calculator. Fam Med. 2019;51(2):185-192.

19. Martinez-Bianchi V, Frank B, Edgoose J, et al. Addressing family medicine's capacity to improve health equity through collaboration, accountability, and coalition building. Fam Med. 2019;51(2):198-202.

20. Kelly C, Coutinho AC, Goldgar C. Collaborating to achieve the optimal family medicine workforce. Fam Med 2019;51(2):149-158. 